\title{
RESIDUAL HEAT ESTIMATION OF NUCLEAR FUEL IN ENERGY WELL REACTOR
}

\author{
Jana ŠošKová ${ }^{a, *}$, Antonio Dambrosio $^{b}$, Guido Mazzini $^{b}$, Marek RuŠČáK ${ }^{b}$ \\ ${ }^{a}$ Czech Technical University in Prague, Faculty of Nuclear Sciences and Physical Engineering, Department of \\ Nuclear Reactors, V Holešovičkách 2, 18000 Prague 8, Czech Republic

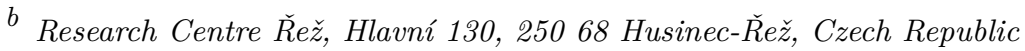 \\ * corresponding author: jana.soskova@email.cz
}

ABstract. Energy Well (EW) is a concept of a small modular reactor, designed as a source of energy for places with low infrastructure. Its design combines TRISO fuel particles, graphite moderator and molten salt coolant. One of key features is that the active core is small and therefore easy to transport. Residual heat estimation of EW fuel assembly is conducted using two different computation codes, SCALE and SERPENT. The obtained residual heat power is then used as an input in TRACE model of the EW to obtain the development of residual temperature in the coolant in the core inlet and outlet and also maximum temperature on the outer side of a fuel slab. The resulting temperatures are below the operational temperature.

KEYworDs: Small modular reactor, Energy Well, TRISO fuel, liquid salt FLiBe, SCALE, SERPENT, decay heat.

\section{INTRODUCTION}

Over the last few decades the nominal power of light water reactors was being increased. Considering current technologies for fuel and materials as well as current safety requirements the limits are being reached and therefore other options for nuclear energy sources are being explored. Small modular reactors were and are in development for decades. Recently they have been gaining more attention due to the relatively small upfront capital investments as well as the ability to provide energy for remote areas off the main grid system. One of the key features of any new reactor designs is inherent safety. As a part of verification of small modular reactor Energy Well design, a code-to-code comparison of residual heat of its fuel is conducted.

\section{ENERGY WELL}

Energy Well is a concept of a small modular reactor, specifically Fluoride-Salt-Cooled High-Temperature Reactor with TRISO fuel particles, graphite moderator and liquid salt FLiBe as a coolant. More details regarding the design of $\mathrm{EW}$ can be found in Section 2.1

Reactor Energy Well is to serve as a source of energy and heat for places with low infrastructure. The power is set to $20 \mathrm{MWt}$ with the expected time of nominal operation being 7 years. The whole power plant has modular construction and the reactor including primary circuit would be transportable to the place of need and afterwards taken back to the factory where it was made. The unique design of the reactor is based on an AHTR concept from Oak Ridge National Laboratory (ORNL), which is further described in studies
[1] and [2]. The key feature of EW is transportability, therefore the core shroud will serve also as a transport container for used fuel. 3.

\subsection{Design OF EW REACTOR}

As it was said above, the EW design was inspired by the AHTR concept and therefore a part of dimensions and material composition used in the EW design is identical to those in the aforementioned studies. However, in some cases adjustments were made so that the final concept was able to meet the requirements of the project, such as low power and smaller size that allows for easy transport.

The active core consists of 19 hexagonal fuel assemblies with active height being $220 \mathrm{~cm}$. Between the assemblies there is a space $1.8 \mathrm{~cm}$ wide and filled with coolant in the form of liquid salt FLiBe. The equivalent diameter of the active core is $214.2 \mathrm{~cm}$ and the diameter including radial reflector is $320 \mathrm{~cm}$.

The material composition and horizontal dimensions of a fuel assembly are identical to figures described in 11. The distance between two parallel outer faces of a fuel channel box which encloses the assembly is $45 \mathrm{~cm}$. The box is made of $1 \mathrm{~cm}$ thick carbon-carbon composite with density $1.95 \mathrm{~g} / \mathrm{cm}^{3}$. The assembly can be divided into three symmetrical segments, each including six fuel plates. These segments are separated by a graphite support structure. In each assembly there is a Y-shaped control rod in the support structure, save for the middle assembly that has no rod due to the placement of the heat exchanger between primary and secondary circuit. This assembly also has lower fuel enrichment.

The control rod is the single tool for controlling reactivity. The material of the absorber is $\mathrm{B}_{4} \mathrm{C}$ with 


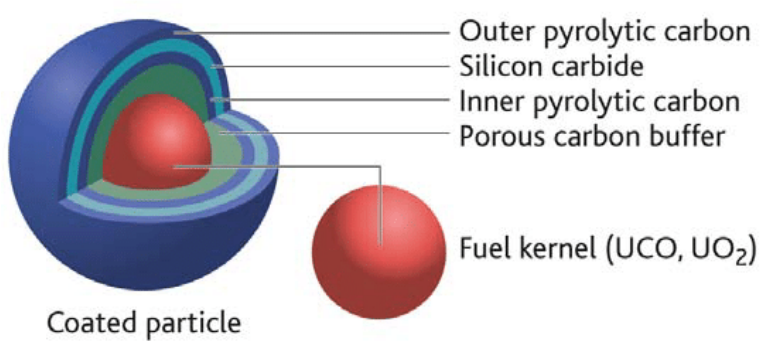

Figure 1. TRISO fuel particle. Picture taken from [6] .

natural boron. The density is $1.79 \mathrm{~g} \mathrm{~cm}^{-3}$. The thickness of a blade of the control rod is $1 \mathrm{~cm}$. Different control rods are placed in the radial reflector of the active core and those help to keep sufficient subcriticality when the reactor is in shutdown.

Each fuel plate is $2.55 \mathrm{~cm}$ thick. Between two fuel plates there is a cooling channel $0.7 \mathrm{~cm}$ thick. The first and the last cooling channel in each segment has only half thickness $(0.35 \mathrm{~cm})$. The fuel plate has a sandwich construction, where two fuel slabs are separated by a graphite plate. The fuel slabs consist of a graphite matrix with TRISO fuel particles embedded with packing fraction $25 \%$. The fuel slabs are also covered by a layer of C-C composite on the outer sides to prevent erosion of TRISO particles into the coolant.

Attached at the end of the article there is Figure 8 that displays the described geometry of the fuel assembly. In the pictures, brown stands for fuel plates, blue represents FLiBe coolant, the support structure and the assembly box are shown in grey and red stands for the control rod.

\subsubsection{TRISO PARTICLE}

The idea of coated fuel particles dates back to 1957, when it was first suggested by Roy Huddle [4] as a part of the Dragon project. Since then, the particles were used in a variety of experimental reactors around the world. Currently, the TRISO fuel is included in a basic reactor design for VHTR Gen IV reactor. [5] The word TRISO comes from the term tristructural-isotropic. As the name suggests, there are three isotropic materials coating the fuel itself. Those are graphite, silicon carbide and pyrolytic carbon. The materials are enveloping the fuel kernel in four layers as shown in Figure 1

There were chosen TRISO particles with diameter $0.4235 \mathrm{~mm}$ with UCO fuel kernel (enrichment $15 \%$ ) for EW design. The failiure temperature for TRISO fuel is $1873 \mathrm{~K}$, which is well above the highest temperature reached in EW (the fuel temperature $1200 \mathrm{~K}$ ). [3]

\subsubsection{FLiBE COOLANT}

The binary system $\mathrm{LiF}-\mathrm{BeF}_{2}$ has two eutectic invariant equilibria in its phase diagram. One at the temperature $T=636 \mathrm{~K}$ and the share of $\mathrm{BeF}_{2}$ in the mix $x\left(\mathrm{BeF}_{2}\right)=0.517$. The other can be found at $T=729 \mathrm{~K}$ and $x\left(\mathrm{BeF}_{2}\right)=0.328$. For EW design the use of $2 \mathrm{LiF}$ $\mathrm{BeF}_{2}$ was chosen with the melting point $t=732 \mathrm{~K}$ and boiling point being $t=1703 \mathrm{~K}$. With inlet and outlet coolant temperatures being $923 \mathrm{~K}$ and $973 \mathrm{~K}$ respectively, FLiBe allows the reactor to operate at atmospheric pressure. It was also chosen for its thermodynamic properties, such as the high volumetric heat capacity $c_{v}=4540 \mathrm{~kJ} \cdot \mathrm{m}^{-3} \cdot \mathrm{K}^{-1}$. [7] FLiBe properties give EW inherent safety because even in case of loss of flow accident the natural circulation would sufficiently cool the reactor. As for neutronics, the lithium has to be highly isotopically enriched in ${ }^{7} \mathrm{Li}$ as ${ }^{6} \mathrm{Li}$ has a high thermal neutron capture cross section. The beryllium also provides some moderation. Fluoride salts are highly corrosive with $\mathrm{Cu}$ and therefore the use of Nickel alloys is necessary for construction materials. The alloys currently under consideration are $\mathrm{H} 800, \mathrm{MoNiCr}$ and Hastelloy N. [3, 8]

\section{Codes}

For residual heat estimation there were overall three codes used: SCALE, SERPENT and TRACE. SCALE was chosen as a deterministic code while SERPENT is a stochastic code. The decay heat power of an assembly was determined using both codes, giving the option of code-to-code comparison. The resulting values of decay heat power were then used as an input in an existing TRACE model of a power plant with EW reactor to gain maximum cladding temperature and an inlet and outlet coolant temperatures.

SCALE 6.1 is a code package developed by the ORNL. Its computational modules include three deterministic radiation transport solvers. It can preform multiple tasks and fuel depletion and decay are among them. The package consists of different modules. The modules used in this case include: TRITON, ORIGEN-S, NEWT and OPUS. These are all included in a depletion sequence t-depl which was used in this case. ORIGEN-S starts the depletion of the material selected for depletion in the input. TRITON updates the data calculated with ORIGEN-S and NEWT is used for the flux post-processing in case of a 2D depletion. The OPUS module produces a condensed output file with data from output generated by the ORIGEN$\mathrm{S}$ code. The OPUS tables contain information about total and individual nuclide or element concentrations in units set in the input. [9] [10]

SERPENT 2 is a Monte Carlo reactor physics burnup calculation code developed by the VTT Technical Research Centre of Finland. It is a 3D code and it was designed specifically for lattice physics applications. The output is similar to SCALE. [11] [12]

\section{Model DESCRIPTION}

\subsection{SCALE}

The depletion model of an EW fuel assembly was made to gain the assembly's decay heat power in watts at 
different points in time from the OPUS module. The chosen nuclear data library is ENDF/B-VII.0.

The composition of materials was specified for the fuel slab, FLiBe coolant, the graphites (in accordance with the densities) and for $\mathrm{B}_{4} \mathrm{C}$. For reasons further explained in the following paragraph, the fuel was defined as a homogenous mixture, with the density calculated from overall volume and weight.

As for celldata, the only deterministic calculation applicable to this geometry in SCALE 6.2.3 is latticecell. Recently there was some development of the doublehet calculation, which keepsw the double heterogenity of the fuel slabs with TRISO particles, however, that is only applicable in KENO module of SCALE which is Monte Carlo based. In this case, there has to be a deterministic calculation in order to make a comparison with SERPENT which is a Monte Carlo code.

In OPUS the units were set to watts.

The geometry itself contains only two units. A global unit with unit no.1 surrounded by FLiBe and the unit 1 itself, where the location of each coolant channel and each fuel element as well as all the other structures is given as a distance from the centre in centimeters. The unit is placed in a rhexagonal type array. This geometry setting requires a dense grid as almost the whole assembly is described in one unit and not in multiple units with their own grids.

The boundaries are set to white, meaning an isotropic return at boundary.

The resulting geometry is shown in Figure 2, where graphite is in yellow, green and also dark blue (which is hardly visible due to the dense grid), FLiBe is in azure and peach, the control rod is in magenta and the fuel slabs are red.

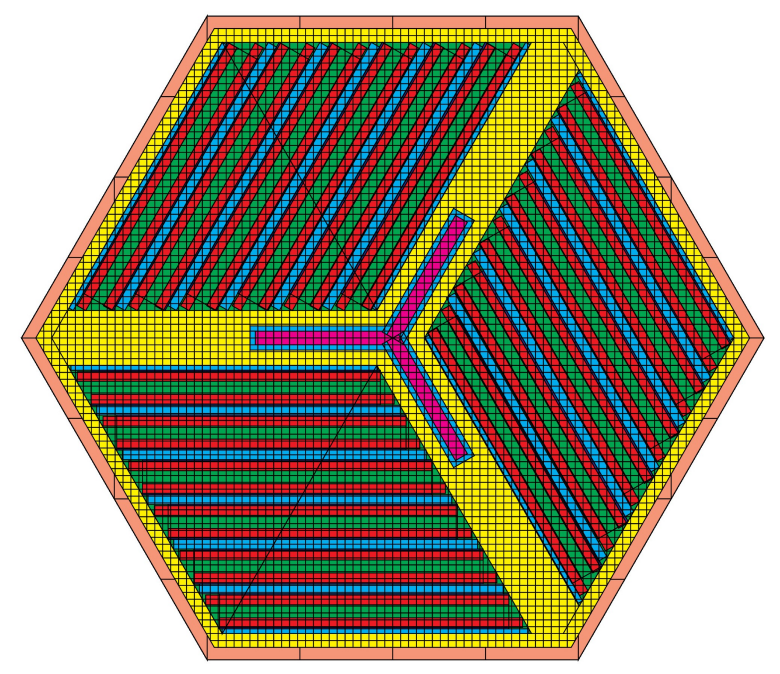

Figure 2. Geometry of EW fuel assembly in SCALE.

\subsection{SERPENT}

While in SCALE the model was done for one assembly, in SERPENT there is a model for the whole active core. In order to gain results fitting for code-tocode comparison, the existing SERPENT model was simplified to include just one assembly as well. The parameters used were corresponding to the ones used in SCALE model. The geometry is shown in Figure 3 where the graphite is bright red and light blue, FLiBe is dark red and dark blue and the fuel area is red with black grains.

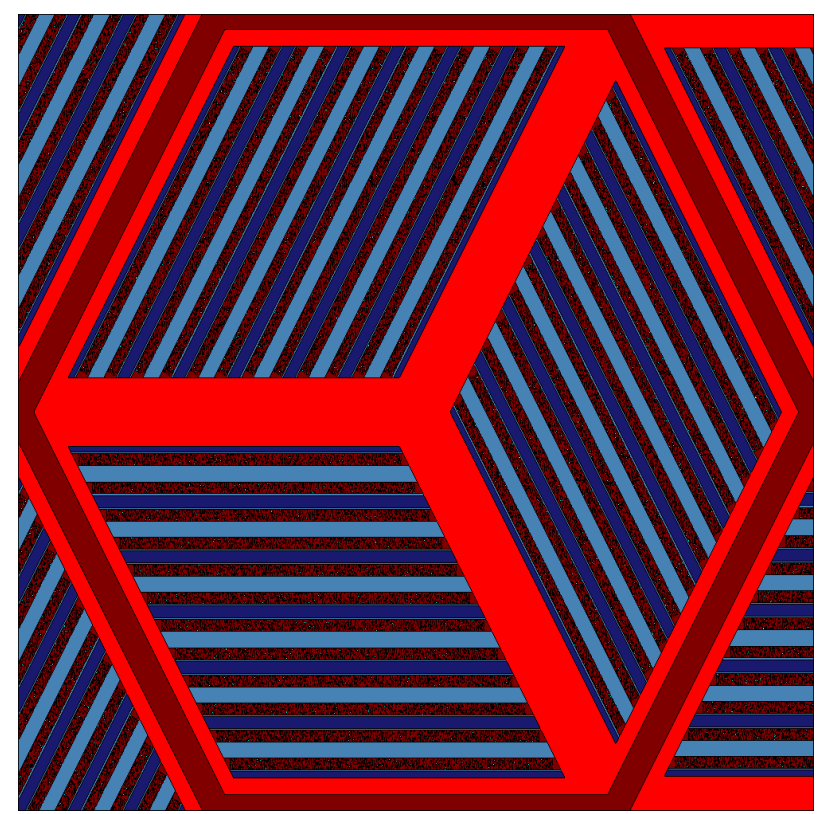

Figure 3. Geometry of EW fuel assembly in SERPENT.

\section{Results}

The decay heat of an EW assembly was obtained using deterministic and stochastic codes. The values were then normalized to the nominal power of the reactor. The comparison of the amount of ${ }^{235} \mathrm{U}$ was made to show that both codes were in agreement. This is shown in Tab. 1 The difference between the amount of uranium at time zero is $82.32 \mathrm{~g}$. This difference presents less than $1.4 \%$. A part of it is contributed to geometrical differences between the SCALE and SERPENT models. Said difference is $76.68 \mathrm{~g}$ of ${ }^{235} \mathrm{U}$. Then for the following years the difference varies, with maximum of $3.3 \%$.

Results for the decay heat are shown in Figures 4 and 5 Figure 4 shows that a second after shutdown the heat is already below $7 \%$ of the nominal power and is declining exponentially. The drop to the approximately $7 \%$ of the nominal thermal power within the first second after shutdown is of typical occurrence in other reactors. Figure 5 then follows the decline in years. There are small differences in the values obtained from SCALE and SERPENT, the difference being no more than $4.5 \%$. The difference is declining with time, as can be seen in Figure 5 . The SCALE approach is more conservative.

The values of decay power in watts were used as an input in the TRACE model to obtain information 


\begin{tabular}{|c|c|c|}
\hline $\mathrm{t}[\mathrm{y}]$ & $\mathrm{m}[\mathrm{g}]$ SERPENT & $\mathrm{m}[\mathrm{g}] \mathrm{SCALE}$ \\
\hline 0 & 5796.73 & 5714.41 \\
\hline 1 & 5319.98 & 5249.64 \\
\hline 2 & 4878.28 & 4826.77 \\
\hline 3 & 4465.29 & 4438.19 \\
\hline 4 & 4077.16 & 4076.28 \\
\hline 5 & 3712.07 & 3744.46 \\
\hline 6 & 3368.34 & 3434.36 \\
\hline 7 & 3044.81 & 3145.97 \\
\hline
\end{tabular}

TABLE 1. The amount of ${ }^{235} \mathrm{U}$ in one assembly as calculated by SCALE and SERPENT during the seven year burnup.

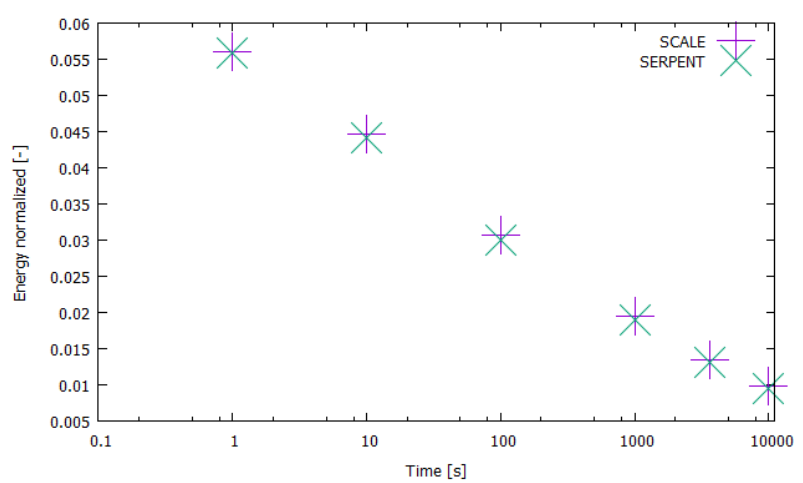

Figure 4. The ratio of decay heat power to nominal power for both SCALE and SERPENT in seconds after shutdown. The time axis is logarithmic.

about temperature. Figure 6 shows the maximum temperature on the outer side of a fuel slab. Figure 7 shows the coolant temperature in core inlet and core outlet. Both results are below the operational temperature, which is almost $1000 \mathrm{~K}$ for the outer side of a fuel slab and almost $970 \mathrm{~K}$ for the coolant in core outlet. The difference between SCALE and SERPENT results doesn't exceed $3 \mathrm{~K}$ which is an acceptable result.

\section{Conclusions}

The models of EW fuel assembly in SCALE and SERPENT were used to obtain the decay heat power. In both cases the resulting decay heats fall well underneath the $7 \%$ ratio. The difference doesn't exceed $4.5 \%$. The results were used in the TRACE model of EW to obtain the values of the maximum temperature on the outer side of a fuel slab and the core inlet and outlet coolant temperatures. In both cases the results are below the operational temperature, which is almost $1000 \mathrm{~K}$ for the outer side of a fuel slab and almost $970 \mathrm{~K}$ for the coolant in core outlet. The difference in the resulting temperatures is negligible.

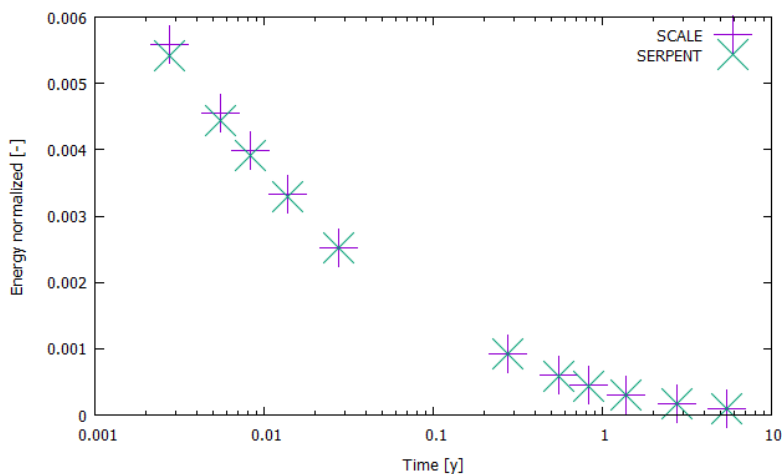

FiguRE 5. The ratio of decay heat power to nominal power for both SCALE and SERPENT in years. The time axis is logarithmic.

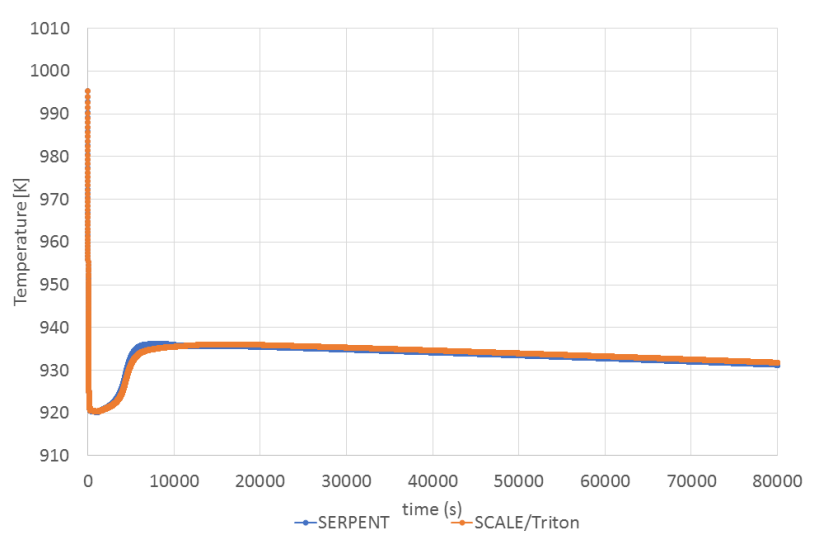

Figure 6 . The chart shows the development of maximum temperature on the outer side of a fuel slab in Kelvin. The time after shutdown is in seconds. The results are shown for SCALE and SERPENT.

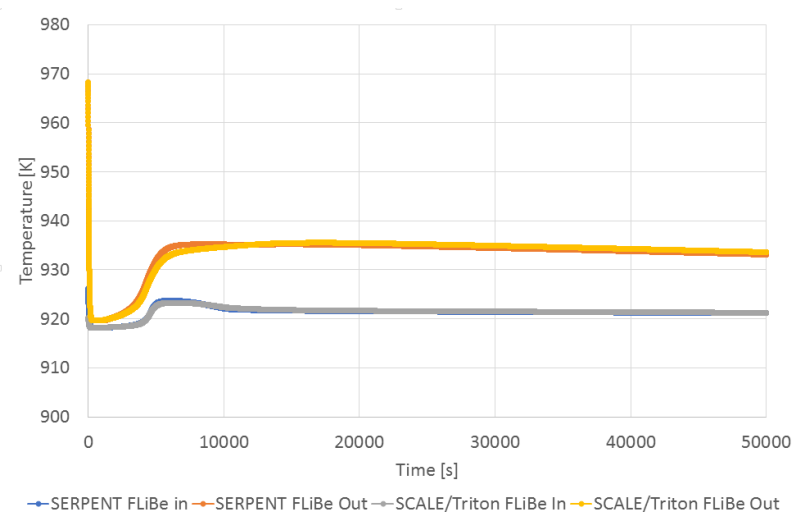

Figure 7. The chart shows the development of coolant temperature in core inlet and core outlet in Kelvin. The time after shutdown is in seconds. The results are shown for SCALE and SERPENT.

\section{ACKNOWLEDGEMENTS}

EW project was supported by CV Rez, Czech Technical University in Prague and TACR's THETA programme. 

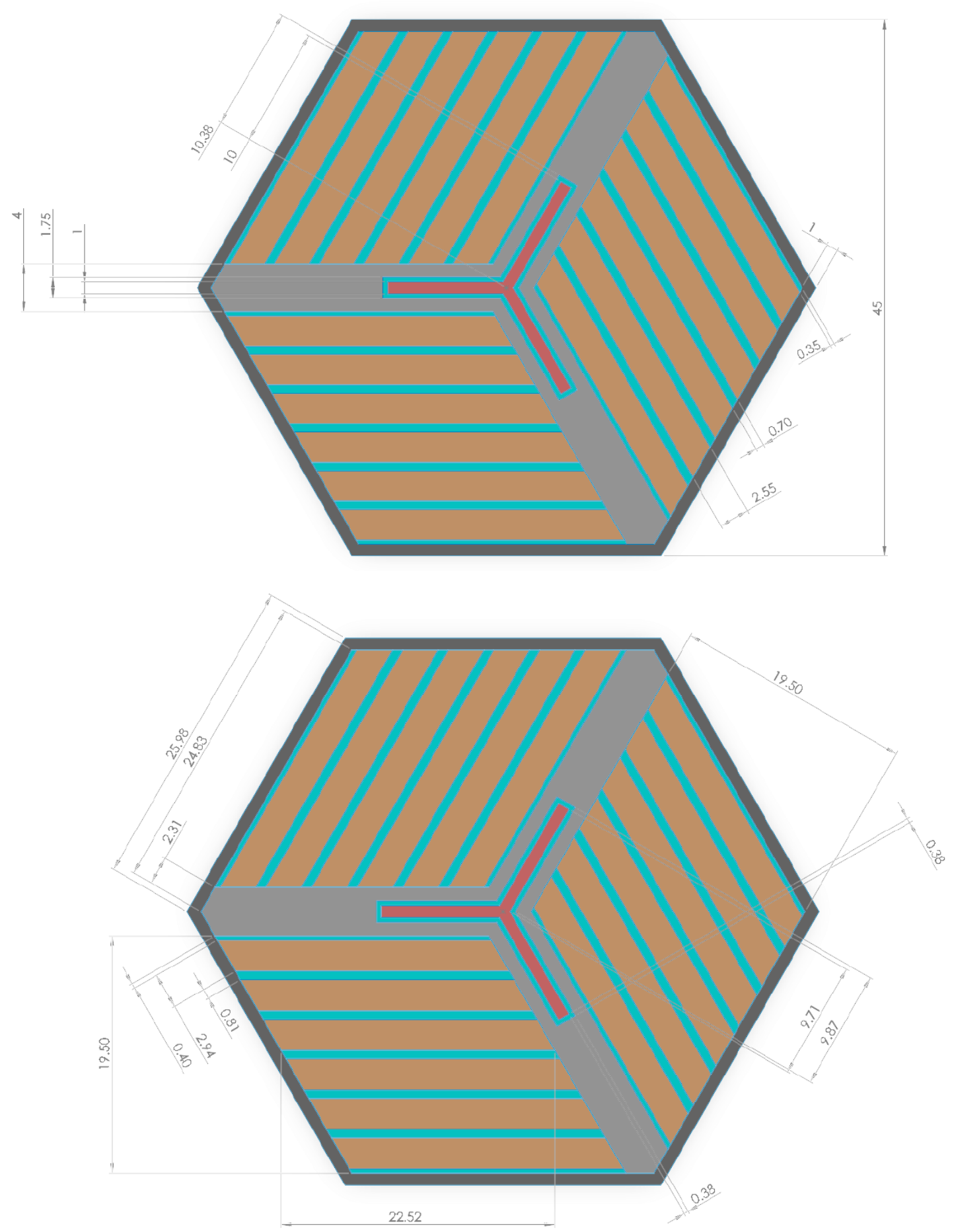

Figure 8. Assembly dimensions in $\mathrm{cm}$. Picture adopted from [1] 


\section{REFERENCES}

[1] B. Petrovic, I. Maldonado. Fuel and Core Design Options to Overcome the Heavy Metal Loading Limit and Improve Performance and Safety of Liquid Salt Cooled Reactors. Tech. Rep. DOE/NEUP-12-3870, 1253940, 2016. DOI:10.2172/1253940

[2] D. E. Holcomb, D. Ilas, V. K. Varma, et al. Core and Refueling Design Studies for the Advanced High Temperature Reactor. Tech. Rep. ORNL/TM-2011/365, 1025857, 2011. DOI:10.2172/1025857

[3] E. Losa, M. Ruščák, G. Mazzini. Návrh aktivní zóny a studie proveditelnosti malého modulárního reaktoru chlazeného roztavenou solí.

[4] K. Verfondern, H. Nabielek, J. Kendall. Coated particle fuel for high temperature gas cooled reactors. Nuclear Engineering and Technology 39:603 - 616, 2007.

[5] G. D. Del Cul. TRISO-Coated Fuel Processing to Support High Temperature Gas-Cooled Reactors. Tech. Rep. ORNL/TM-2002/156, 814326, 2002. DOI: $10.2172 / 814326$
[6] J. Hales, R. Williamson, S. Novascone, et al. Multidimensional multiphysics simulation of triso particle fuel. Journal of Nuclear Materials 443(1):531 543, 2013. DOI:10.1016/j.jnucmat.2013.07.070

[7] J. Richard, D. Wang, G. Yoder, et al. Implementation of liquid salt working fluids into TRACE. vol. 3, pp. 1775-1785. 2014.

[8] O. Benes, R. Konings. 4 - Thermodynamic Calculations of Molten-Salt Reactor Fuel Systems. In F. Lantelme, H. Groult (eds.), Molten Salts Chemistry, pp. 49 - 78. Elsevier, Oxford, 2013. DOI:10.1016/B978-0-12-398538-5.00004-4

[9] A. Dambrosio, M. Ruscak, M. Guido, A. Musa. Neutronic analysis of the LVR-15 research reactor using the PARCS code. Annals of Nuclear Energy 117:145-154, 2018. DOI:10.1016/j.anucene.2018.03.009.

[10] B. T. Rearden, M. A. Jessee. SCALE code system 2018. DOI:10.2172/1426571

[11] M. Ruscak. Rod ejection simulation on VVER 1000/320 core using PARCS/TRACE. p. 165, 2016.

[12] J. Leppänen. Serpent-a continuous-energy monte carlo reactor physics burnup calculation code. VTT Technical Research Centre of Finland 4, 2013. 